\title{
Overexpression of CD164 in oral cavity squamous cell carcinoma predicts a favourable prognosis
}

\author{
JIA-HONG CHEN ${ }^{1}$, WEI-LIANG CHEN ${ }^{2}$, JAMES YI-HSIN CHAN ${ }^{2,3}$, \\ YUAN-WU CHEN ${ }^{4}$, YI-JEN PENG ${ }^{5}$, MING-FANG CHENG ${ }^{6}$ and CHUN-SHU LIN $^{7}$
}

\begin{abstract}
Divisions of ${ }^{1}$ Medical Oncology and Haematology and ${ }^{2}$ Family Medicine; ${ }^{3}$ Graduate Institute of Medical Sciences; Departments of ${ }^{4}$ Oral and Maxillofacial Surgery and ${ }^{5}$ Pathology, Tri-Service General Hospital, National Defense Medical Centre, Taipei 11490; ${ }^{6}$ Division of Histological and Clinical Pathology, Hualien Armed Forces General Hospital, Hualien 97144; ${ }^{7}$ Department of Radiation Oncology, Tri-Service General Hospital, National Defense Medical Centre, Taipei 11490, Taiwan, R.O.C.
\end{abstract}

Received May 10, 2016; Accepted June 9, 2017

DOI: $10.3892 / \mathrm{ol} .2017 .6966$

\begin{abstract}
The aim of the present study was to investigate the association between cluster of differentiation (CD) 164 expression with clinicopathological parameters and prognosis among patients with oral cavity squamous cell carcinoma (OSCC). The present study retrospectively reviewed 70 patients with OSCC who underwent curative primary surgery. A number of patients subsequently received postoperative chemoradiotherapy although the specimens were not exposed to radiation or chemotherapy prior to anti-CD164 antibody immunohistochemical staining. CD164 overexpression was arbitrarily defined as exhibiting an $\mathrm{H}$-score of $\geq 120$. Univariate and multivariate analyses were performed for sex, age, American Joint Committee on Cancer stage, tumour location, histological grade, surgical margin and $\mathrm{H}$-score. The 5-year overall survival rate was $54.4 \%$ and the median follow-up time was 46 months for surviving patients. Univariate analyses revealed that a low overall survival rate was associated with advanced-stage disease $(\mathrm{P}<0.001)$, buccogingival tumour location $(\mathrm{P}=0.038)$ and a CD164 H-score of $<120(\mathrm{P}=0.016)$. Multivariate Cox's regression analyses revealed that poor overall survival rate was associated with advanced-stage disease $(\mathrm{P}=0.001)$ and a CD164 H-score of $<120(\mathrm{P}=0.04)$. CD164 overexpression in OSCC was associated with favourable survival rate. Thus, CD164 expression may be a clinically useful predictor of prognosis in patients with OSCC.
\end{abstract}

Correspondence to: Dr Chun-Shu Lin, Department of Radiation Oncology, Tri-Service General Hospital, National Defense Medical Centre, 325 Chenggong Road, Taipei 11490, Taiwan, R.O.C.

E-mail: chunshulin@gmail.com

Key words: cluster of differentiation 164, endolyn, oral cavity cancer, oral cavity squamous cell carcinoma, survival

\section{Introduction}

Oral cavity cancer represents $\sim 2.6$ and $1.5 \%$ of all malignancies among males and females, respectively and is a major global public health problem (1). The 2012 cancer registry report from the Taiwan Health Promotion Administration of the Ministry of Health and Welfare indicated that the incidence of oral cavity cancer was 20/100,000 and the annual mortality rate was $11 / 100,000$, making it the fifth most common cause of cancer-related mortality in Taiwan. On the basis of histological data, oral cavity squamous cell carcinoma (OSCC) accounts for $>90 \%$ of all oral cavity cancer cases; this histological subgroup is characterized by increased rates of tumour cell migration, invasion and metastasis (2).

Marked progress has been made in the treatment of OSCC. Wide excision of the tumour with neck dissection is the primary form of treatment with concurrent postoperative chemoradiotherapy improving outcomes for operable cases of locally advanced $\operatorname{OSCC}(3,4)$. However, despite the availability of multidisciplinary treatment, the survival rate for oral cavity cancer over the last decade has remained poor and remains a major cause of mortality $(5,6)$. Furthermore, radiotherapy may lead to side effects including trismus and xerostomia $(7,8)$. Therefore, several studies have attempted to identify prognostic pathological markers, including human papillomavirus (HPV) infection, which may help to decrease radiation doses in patients with favourable prognostic factors for head and neck cancer $(9,10)$.

Cluster of differentiation (CD) 164, a glycoprotein and type I integral transmembrane sialomucin that is also known as endolyn or MGC-24 is encoded by the CD164 gene located on human chromosome 6q21 (11). Three isoforms of CD164 have been identified (12-14). CD164 serves important roles in regulating proliferation, adhesion and differentiation in progenitor and hematopoietic stem cells as well as negative regulation of haematopoiesis (15). However, few cancer-associated studies have examined this protein and, to the best of our knowledge, no studies have considered it in the context of head and neck cancer (16-22). Therefore, the present study aimed to investigate the association of CD164 expression 
with clinicopathological parameters and prognosis in patients with OSCC.

\section{Materials and methods}

Patients. The present study retrospectively reviewed 70 patients who were diagnosed with malignant OSCC between January 2000 and December 2010 at the Tri-Service General Hospital (Taipei, Taiwan). This sample only included patients with OSCC who underwent planned curative primary surgery with or without adjuvant chemoradiotherapy. Patients with other histological diagnoses including acinic cell carcinoma, adenoid cystic carcinoma, verrucous carcinoma, adenocarcinoma, sarcoma and mucoepidermoid carcinoma were excluded. Patients with metastatic oral cavity cancer, synchronous oral cancers or a history of malignancy or treatment at other hospitals were also excluded.

The present study was approved by the institutional review board of Tri-Service General Hospital (TSGH1-105-05-012) and the methods were carried out in accordance with the approved guidelines. Informed written consent was obtained from all subjects. The 70 eligible patients included 63 males and 7 females with an age range of between 29 and 72 years (median, 51 years). Pathological stages were classified in all 70 cases according to the 2010 staging criteria of the American Joint Committee on Cancer (AJCC) (23).

Treatment. All patients underwent standard primary surgery according to their clinical stage $(5,6)$. Wide excision with supraomohyoid neck dissection was performed for early-stage cases; wide excision with ipsilateral modified radical neck, ipsilateral radical neck or bilateral radical neck dissection was performed for locally advanced cases. The majority of patients required flap reconstruction due to the large wound that was created by the surgical procedures.

A total of 21 patients (30\%) underwent surgery alone, with the remaining 49 patients (70\%) undergoing postoperative radiotherapy with or without chemotherapy. The radiation fields included the tumour bed, the ipsilateral upper neck for early-stage cases and the ipsilateral whole neck or bilateral neck for locally advanced cases. The radiation technique was intensity modulated radiotherapy with prescribed doses of between 60 and $66 \mathrm{~Gy}$ for the tumour bed and upper neck, and between 50 and $54 \mathrm{~Gy}$ for the lower neck with a daily fraction size of between 1.8 and $2.2 \mathrm{~Gy}$.

All 43 cases of stage III-IV disease underwent postoperative concurrent chemoradiotherapy. The early standard for chemotherapy was previously cisplatin $\left(80-100 \mathrm{mg} / \mathrm{m}^{2}\right.$ per day on days 1, 22 and 43) during the radiotherapy (24). However, since 2007 , weekly cisplatin chemotherapy $\left(30-40 \mathrm{mg} / \mathrm{m}^{2}\right)$ has also been considered a treatment option during radiotherapy $(6,25)$. Following the concurrent chemoradiotherapy, 3 cycles of monthly adjuvant chemotherapy were administered to high-risk patients (cisplatin at $80 \mathrm{mg} / \mathrm{m}^{2}$ on day 1 and fluorouracil at $1,000 \mathrm{mg} / \mathrm{m}^{2}$ on days $1-4$ as a $96 \mathrm{~h}$ infusion for each cycle). Overall survival time was defined as the time from the date of diagnosis to the date of mortality from any cause.

Tissue specimens and immunohistochemistry. Tumour specimens were soaked in $10 \% \mathrm{v} / \mathrm{v}$ formalin solution at room temperature for $24 \mathrm{~h}$, and then the specimens were embedded in paraffin. The paraffin-embedded tumour tissues from the 70 patients prior to chemoradiotherapy treatment were obtained from the department of pathology, and a tissue microarray slide was constructed. To construct the tissue microarray, one core of $2 \mathrm{~mm}$ in diameter was taken from a selected area of each paraffin-embedded tumour tissue. The tissue microarray slide showed uniform staining as the original paraffin-embedded specimens. Serial $4 \mu \mathrm{m}$ sections were excised and stained by a Leica autostainer XL (Leica Biosystems, Nussloch, Germany) for standard hematoxylin and eosin staining. Briefly, the procedure of hematoxylin and eosin staining included xylene $16 \mathrm{~min}$, absolute alcohol $4 \mathrm{~min}$ $30 \mathrm{sec}$, wash out $1 \mathrm{~min} 30 \mathrm{sec}$, hematoxylin $4 \mathrm{~min}$, wash out $3 \mathrm{~min}, 0.1 \% \mathrm{HCL} 40 \mathrm{~min}$, wash out $5 \mathrm{~min}$, absolute alcohol $2 \mathrm{~min}$, eosin $30 \mathrm{sec}$, absolute alcohol $5 \mathrm{~min} 10 \mathrm{sec}$ and xylene $4 \mathrm{~min} 20 \mathrm{sec}$. The histopathological diagnosis of OSCC was confirmed by two experienced pathologists. On the basis of the histopathological grading, 17 tumours (24\%) exhibited good differentiation, 37 tumours (53\%) exhibited moderate differentiation and 16 tumours (23\%) exhibited poor differentiation. The immunohistochemical staining for CD164 was performed according to the standard protocol (21). The sections were dried overnight at $37^{\circ} \mathrm{C}$ and were deparaffinized using xylene. All sections were treated using an antigen retrieval solution (Target Retrieval; Dako; Agilent Technologies, Inc., Santa Clara, CA, USA) at $95^{\circ} \mathrm{C}$ for 15 min before incubation overnight at $4^{\circ} \mathrm{C}$ with a polyclonal sheep anti-human CD164 antibody (1:100; R\&D Systems, Inc., Minneapolis, MN, USA). A dilution of 1:100 purified rabbit anti-human CD164 antibody (HPA010636; Sigma-Aldrich; Merck KGaA, Darmstadt, Germany) was set for $60 \mathrm{~min}$ at room temperature, and secondary biotin-linked sheep anti-immunoglobulin antibody (B3275; Sigma-Aldrich; Merck KGaA) for $30 \mathrm{~min}$ at room temperature. The sections were developed using diaminobenzidine and counterstained using haematoxylin. These were incubated in horseradish peroxidase-conjugated streptavidin (Dako; Agilent Technologies, Inc.) for $2 \mathrm{~min}$ at room temperature. All slides were examined using Olympus BX51 (magnification, x400) and scored independently by the two pathologists, who were blinded to the patients' clinical information.

As staining intensity and distribution varied, cytoplasmic staining was scored using a 4-point scale $(0$, no staining; $1+$, light staining at high magnification; $2+$, intermediate staining; $3+$, dark staining of linear membrane at low magnification; Fig. 1). Additionally, the percentage of stained cells was estimated for each intensity. The percentage of CD164-stained cells for each intensity was multiplied by the corresponding intensity score to obtain an immunostaining score (H-score) that ranged between 0 and 300 (26).

Statistical analysis. SPSS version 20.0 (IBM Corp., Armonk, NY, USA) was used for all analyses. Pearson's $\chi^{2}$ test and Fisher's exact test were used to evaluate the association of CD164 expression with the patients' clinicopathological characteristics. Cumulative survival rate was evaluated using Kaplan-Meier estimator analysis and the log-rank test. All the independent factors were further tested using Cox's regression for multivariate comparison. $\mathrm{P}<0.05$ was considered to 
Table I. Associations between $\mathrm{H}$-score and patient characteristics.

\begin{tabular}{|c|c|c|c|}
\hline Characteristic & $\begin{array}{c}\text { H-score } \\
<120, \text { n }(\%)\end{array}$ & $\begin{array}{c}\text { H-score } \\
\geq 120, \mathrm{n}(\%)\end{array}$ & P-value \\
\hline All cases & $42(60)$ & $28(40)$ & \\
\hline \multicolumn{4}{|l|}{ Sex } \\
\hline Male & $37(88)$ & $26(93)$ & 0.515 \\
\hline Female & $5(12)$ & $2(7)$ & \\
\hline \multicolumn{4}{|l|}{ Age, years } \\
\hline$<51$ & $28(67)$ & $15(54)$ & 0.324 \\
\hline$\geq 51$ & $14(33)$ & $13(46)$ & \\
\hline \multicolumn{4}{|l|}{ AJCC stage } \\
\hline I-II & $31(38)$ & $12(39)$ & 0.270 \\
\hline III-IV & $50(62)$ & $21(42)$ & \\
\hline \multicolumn{4}{|l|}{ Tumour location } \\
\hline Buccal-gingival & $24(57)$ & $12(43)$ & 0.241 \\
\hline Others & $18(43)$ & $14(57)$ & \\
\hline \multicolumn{4}{|l|}{$\begin{array}{l}\text { Histopathological } \\
\text { grade }\end{array}$} \\
\hline 1 & $10(24)$ & $7(25)$ & 0.972 \\
\hline 2 & $22(52)$ & $15(54)$ & \\
\hline 3 & $10(24)$ & $6(21)$ & \\
\hline \multicolumn{4}{|l|}{ Surgical margin } \\
\hline Negative & $36(86)$ & $27(96)$ & 0.143 \\
\hline Positive & $6(14)$ & $1(4)$ & \\
\hline
\end{tabular}

AJCC, American Joint Committee on Cancer.

indicate a statistically significant difference for all known confounding factors, although $\mathrm{P}<0.025$ was used to evaluate the significance of CD164 expression as its clinical relevance was unclear.

\section{Results}

A total of 9 patients (13\%) had stage I disease, 18 patients (26\%) had stage II disease, 16 patients $(23 \%)$ had stage III disease and 27 patients (38\%) had stage IV disease. None of the patients exhibited distant metastases at their presentation. The tongue was the most commonly affected site [30 patients $(43 \%)]$ followed by the buccal mucosa [29 patients $(41 \%)]$, gingiva [7 patients (10\%)], tonsils ( 2 patients), palate (1 patient) and lip (1 patient). At the last follow-up, 34 patients (49\%) had succumbed and 36 patients $(51 \%)$ remained alive. The median follow-up for the surviving patients was 46 months (range, 4-120 months). Among all patients, the 5-year locoregional control and overall survival rates were 48.0 and $54.4 \%$, respectively.

CD164 was primarily detected in the cytoplasm and cell membrane of the cancer cells and in the lymphocytes surrounding the tumours. A total of 17 patients (24\%) exhibited a CD164 staining intensity of 3+, compared with 42 patients $(60 \%)$ for $2+$ and 11 patients $(16 \%)$ for $1+$. The median $\mathrm{H}$-score was 106.5 (range, 23-243) and the samples were arbitrarily classed as having low CD164 expression (H-score <120) or
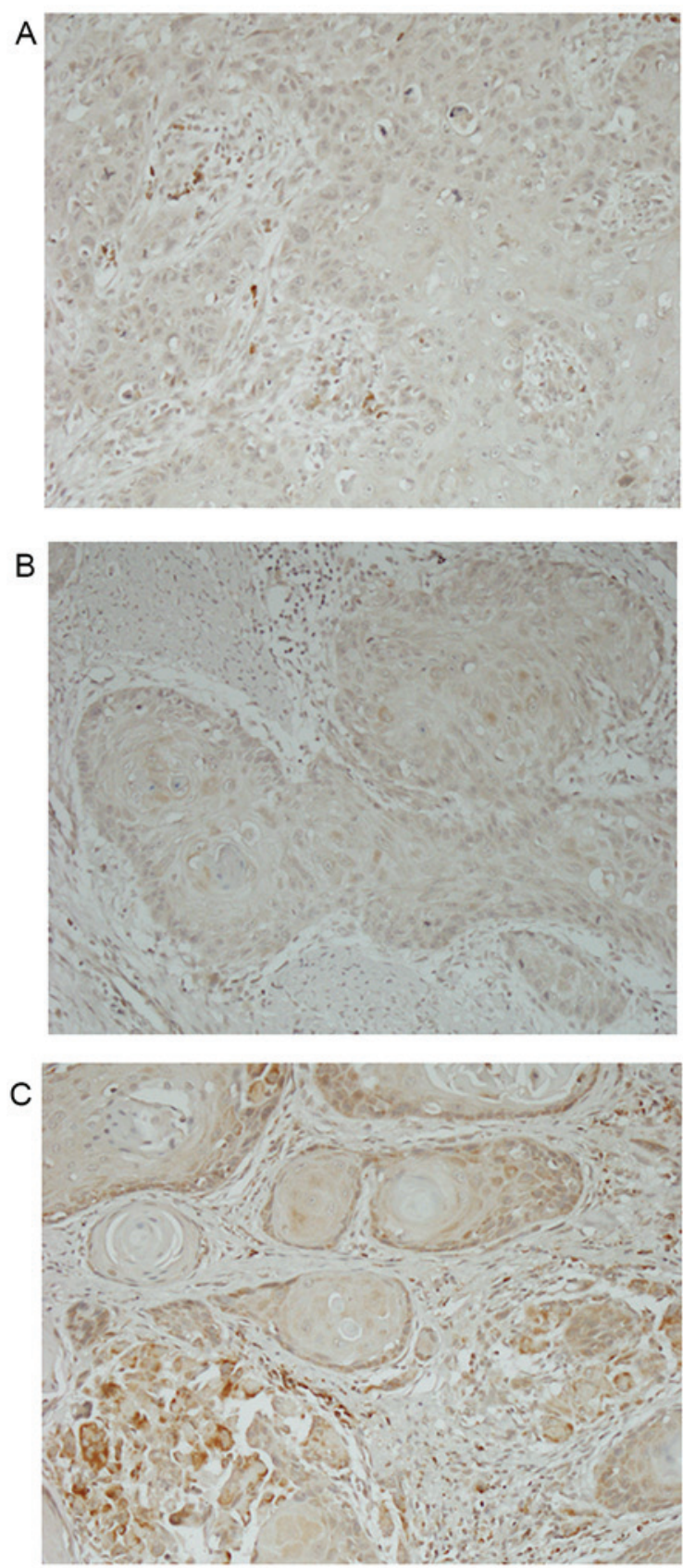

Figure 1. Immunohistochemical staining for CD164 in oral cavity squamous cell carcinoma tissues. Cytoplasmic staining was observed at distinct intensities: (A) $56 \%$ of the tissues exhibiting an intensity of $1+$; (B) $66 \%$ of the tissues exhibiting an intensity of $2+$; and (C) $26 \%$ of the tissues exhibiting an intensity of $3+$. CD164 staining was also observed in the cell membrane and in lymphocytes surrounding the tumour cells. CD, cluster of differentiation.

high CD164 expression (H-score $\geq 120$ ). Table I indicates that the $\mathrm{H}$-score was not significantly associated with known prognostic factors including sex $(\mathrm{P}=0.515)$, age $(\mathrm{P}=0.324)$, AJCC stage $(\mathrm{P}=0.27)$, tumour location $(\mathrm{P}=0.241)$, histopathological grade $(\mathrm{P}=0.972)$ or surgical margin $(\mathrm{P}=0.143)$.

Univariate analyses revealed that no factors were significantly associated with locoregional control (Table II). However, poor overall survival rate was associated with advanced AJCC stage, buccogingival tumour location and low CD164 expression. The 5-year overall survival rates were $84.7 \%$ for patients with stage I-II disease and $35.9 \%$ for patients with stage III-IV 
Table II. Patient characteristics and prognostic factors identified using univariate analysis.

\begin{tabular}{|c|c|c|c|c|c|}
\hline \multirow[b]{2}{*}{ Characteristic } & \multirow[b]{2}{*}{$\mathrm{n}(\%)$} & \multicolumn{2}{|c|}{$\begin{array}{c}5 \text {-year locoregional control } \\
\text { rate }\end{array}$} & \multicolumn{2}{|c|}{$\begin{array}{l}5 \text {-year overall survival } \\
\text { rate }\end{array}$} \\
\hline & & $\%$ & P-value & $\%$ & P-value \\
\hline Sex & & & 0.544 & & 0.871 \\
\hline Male & $63(90)$ & 46.8 & & 54.2 & \\
\hline Female & $7(10)$ & 57.1 & & 57.1 & \\
\hline Age, years & & & 0.553 & & 0.702 \\
\hline$<50$ & $30(43)$ & 56.2 & & 59.8 & \\
\hline$\geq 50$ & $40(57)$ & 42.4 & & 50.1 & \\
\hline AJCC staging & & & 0.327 & & $<0.001$ \\
\hline I-II & $27(39)$ & 61.7 & & 84.7 & \\
\hline III-IV & $43(61)$ & 39.3 & & 35.9 & \\
\hline Tumour location & & & 0.604 & & 0.038 \\
\hline Buccal-gingival & $36(51)$ & 52.8 & & 44.4 & \\
\hline Others & $34(49)$ & 44.3 & & 65.7 & \\
\hline Histological grade & & & 0.975 & & 0.265 \\
\hline 1 & $17(24)$ & 47.1 & & 70.6 & \\
\hline 2 & $37(53)$ & 47.6 & & 47.0 & \\
\hline 3 & $16(23)$ & 53.0 & & 54.5 & \\
\hline Surgical margins & & & 0.507 & & 0.170 \\
\hline Negative & $63(90)$ & 26.8 & & 55.9 & \\
\hline Positive & $7(10)$ & 49.8 & & 38.1 & \\
\hline H-score & & & 0.203 & & 0.016 \\
\hline$<120$ & $42(60)$ & 41.8 & & 42.0 & \\
\hline$\geq 120$ & $28(40)$ & 57.1 & & 74.2 & \\
\hline
\end{tabular}

AJCC, American Joint Committee on Cancer.

disease ( $\mathrm{P}<0.001$; Fig. 2). Buccogingival tumour location was associated with a significantly decreased 5-year overall survival rate $(44.4 \%)$ compared with the other sites $(65.7 \%)$ $(\mathrm{P}=0.038$; Fig. 3). The 5-year overall survival rate was $42.0 \%$ for a low $\mathrm{H}$-score compared with $74.2 \%$ for a high $\mathrm{H}$-score $(\mathrm{P}=0.016$, Fig. 4). All the independent factors were incorporated into the multivariate analyses which revealed that poor survival rate was only associated with AJCC stage III-IV disease $(\mathrm{P}=0.001)$ and a low $\mathrm{H}$-score $(\mathrm{P}=0.040)$.

\section{Discussion}

To the best of our knowledge, the present study is the first to demonstrate that a low CD164 H-score was associated with poor overall survival rate in patients with OSCC. Therefore, CD164 expression may be a useful marker for predicting prognosis in these patients as it is independent of other known clinicopathological parameters including AJCC stage and histopathological grade. Previous studies have attempted to identify parameters that may facilitate decreases in dose- and treatment-associated side effects in head and neck cancer $(9,10)$.

Matsui et al (22) evaluated 92 patients with advanced colorectal carcinoma and analysed the association of CD164 expression with metastatic potential, demonstrating that lower CD164 expression in colon carcinoma was associated with a trend towards invasion into the lymphatic vessels. McGuckin et al (27) identified that CD164 and CD34 exhibit marked co-localization patterns in cells that express the two antigens, suggesting a functional link between the two sialomucins; it was concluded that CD164 and CD34 act as negative regulators of cell proliferation in the transplantation area. Jorgensen-Tye et al (28) also demonstrated that CD164 was a negative regulator of haematopoiesis. Therefore, the results cited above may support the hypothesis that CD164 protects against cell proliferation.

However, other studies have demonstrated that CD164 serves a distinct role in other solid and haematological malignancies. For example, Tang et al (17) examined specimens from human colorectal, breast and ovarian cancer cell lines and revealed that decreased CD164 expression in a human colon cancer cell line significantly inhibited cell proliferation, mobility and metastasis. Thus, it was concluded that CD164 may be a useful target for diagnosing and treating colon cancer. Havens et al (18) analysed the role of CD164 in prostate cancer cell lines and identified that blocking CD164 impaired the ability of prostate cancer cells to adhere to bone marrow endothelial cells and invade extracellular matrices. They also stained human tissue microarrays for CD164 and 


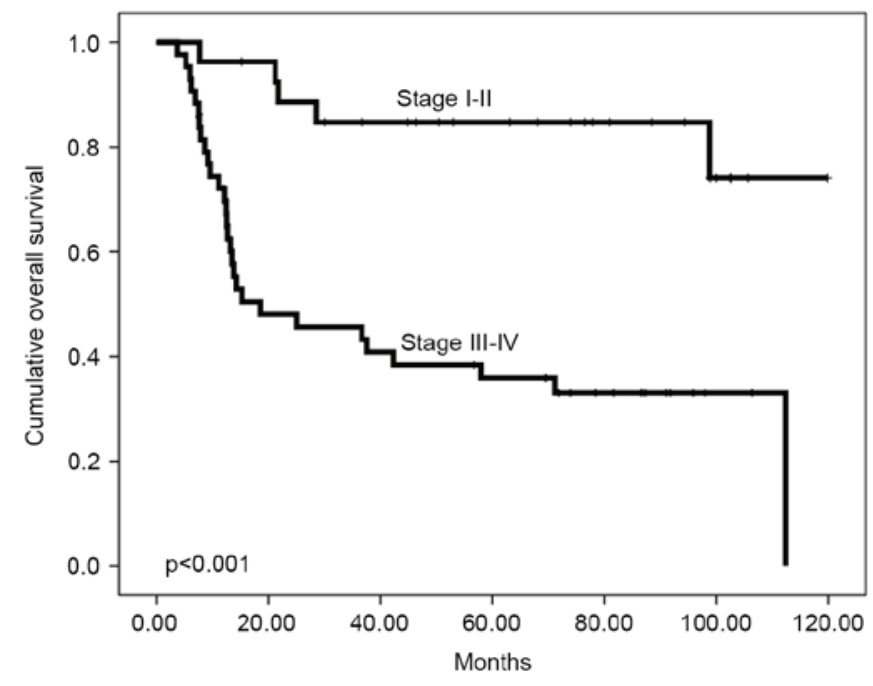

Figure 2. Calculated 5-year overall survival rates were 84.7 and $35.9 \%$ for patients with stage I-II and III-IV disease, respectively $(\mathrm{P}<0.001)$.

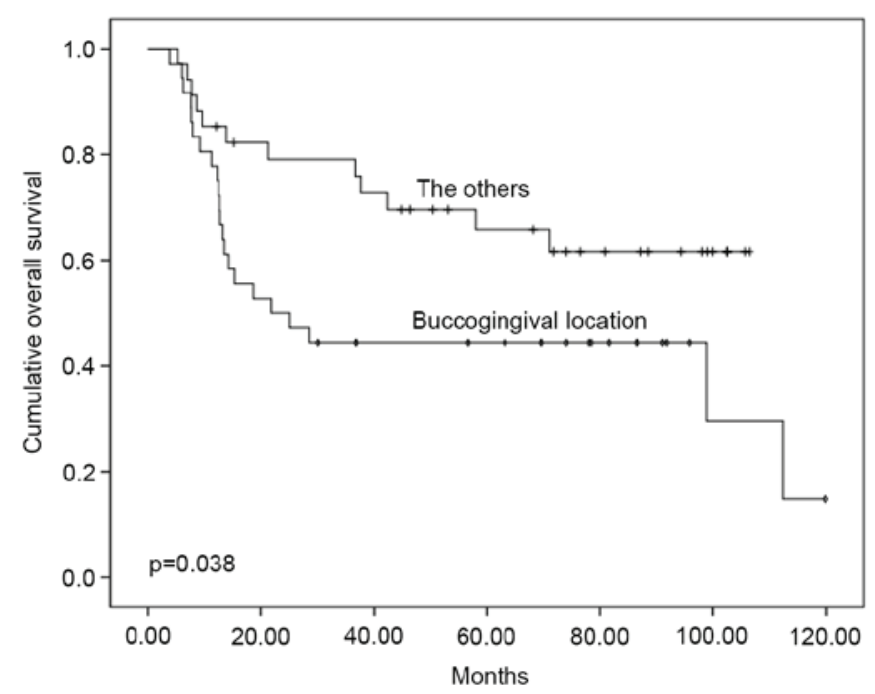

Figure 3. Calculated 5-year overall survival rates were $44.4 \%$ for patients with buccogingival tumour location compared with $65.7 \%$ for patients with tumours located in alternative sites $(\mathrm{P}=0.038)$.

observed a positive association with prostate-specific antigen levels which led to the conclusion that CD164 participates in the localization of prostate cancer cells to the bone marrow and is involved in tumour metastasis. Huang et al (21) evaluated the role of CD164 in ovarian surface epithelial cells from 97 cases and identified that high CD164 expression was significantly associated with high-grade ovarian tumours, advanced-stage disease and tumour metastasis. Thus, they suggested that increased CD164 expression is involved in ovarian cancer progression through the stromal cell-derived factor $1 \mathrm{a} / \mathrm{C}-\mathrm{X}-\mathrm{C}$ chemokine receptor type 4 axis, which promotes tumourigenicity. Wysocka et al (20) evaluated 6 patients with Sézary syndrome and 3 healthy donors, and identified that CD164 could be used to diagnose and monitor cases of the disease. This potential diagnostic role was also observed by Guenova et al (19) who investigated CD164 expression in malignant T-cells from 8 patients with

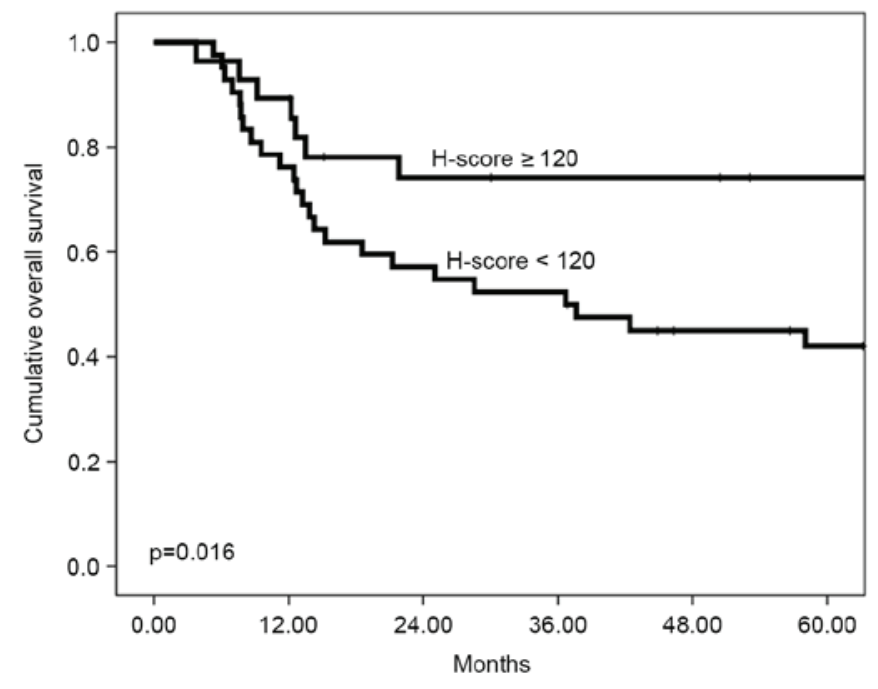

Figure 4. Calculated 5-year overall survival rates were $42.0 \%$ for a low $\mathrm{H}$-score $(<120)$ compared with $74.2 \%$ for a high $\mathrm{H}$-score $(\geq 120 ; \mathrm{P}=0.016)$.

Sézary syndrome and revealed that CD164 expression on CD4 ${ }^{+}$lymphocytes was significantly increased compared with healthy controls. The role of CD164 is ambiguous and remains unclear in the aforementioned studies; the results of the present study support the hypothesis that CD164 inhibits cell proliferation $(17-22,27,28)$.

The present study has several limitations that warrant consideration. First, the sample size was small and a larger cohort study is required to validate the results. Secondly, having used a retrospective design, it is impossible to accurately consider all potential confounding factors (e.g., smoking status, alcohol consumption and paan consumption). Thirdly, H-scores $<120$ were arbitrarily defined as low based on a median score of 106.5, and a larger cohort is required to determine a more accurate and sensitive threshold value. Fourthly, the present study did not consider the cellular and molecular basis of the association of CD164 expression with patient survival rate, although this issue is currently being investigated by the present authors. Fifthly, as a consequence of betel chewing, the majority of OSCC occurs on the tongue, buccal mucosa and gingiva in Taiwan $(5,6)$. However, the three most common sites worldwide for OSCC are the tongue, floor of the mouth and retromolar trigone (29). Owing to this disparity, it remains unknown whether the results of the present study are applicable to other countries or patients with OSCC who do not chew betel.

In conclusion, the results of the present study revealed that CD164 overexpression in patients with OSCC was associated with favourable overall survival rates. Therefore, in addition to the known prognostic factors, CD164 may be another clinically useful parameter.

\section{Acknowledgements}

The authors would like to thank the Cancer Registry Group at the Tri-Service General Hospital for providing the clinical data. The present study was supported by the Tri-Service General Hospital (grant no. TSGH-C106-041). 


\section{References}

1. Ferlay J, Shin HR, Bray F, Forman D, Mathers C and Parkin DM: Estimates of worldwide burden of cancer in 2008: GLOBOCAN 2008. Int J Cancer 127: 2893-2917, 2010.

2. Lin CS, Lin YC, Adebayo BO, Wu A, Chen JH, Peng YJ, Cheng MF, Lee WH, Hsiao M, Chao TY and Yeh CT: Silencing JARID1B suppresses oncogenicity, stemness and increases radiation sensitivity in human oral carcinoma. Cancer Lett 368: $36-45,2015$

3. Cooper JS, Pajak TF, Forastiere AA, Jacobs J, Campbell BH, Saxman SB, Kish JA, Kim HE, Cmelak AJ, Rotman M, et al: Postoperative concurrent radiotherapy and chemotherapy for high-risk squamous-cell carcinoma of the head and neck. N Engl J Med 350: 1937-1944, 2004.

4. Blanchard P, Baujat B, Holostenco V, Bourredjem A, Baey C, Bourhis J, Pignon JP and MACH-CH Collaborative group: Meta-analysis of chemotherapy in head and neck cancer (MACH-NC): A comprehensive analysis by tumour site. Radiother Oncol 100: 33-40, 2011.

5. Lin CS, Jen YM, Cheng MF, Lin YS, Su WF, Hwang JM, Chang LP, Chao HL, Liu DW, Lin HY and Shum WY: Squamous cell carcinoma of the buccal mucosa: An aggressive cancer requiring multimodality treatment. Head Neck 28: 150-157, 2006.

6. Lin CS, Jen YM, Kao WY, Ho CL, Dai MS, Shih CL, Cheng JC, Chang PY, Huang WY and Su YF: Improved outcomes in buccal squamous cell carcinoma. Head Neck 35: 65-71, 2013.

7. Machtay M, Moughan J, Trotti A, Garden AS, Weber RS, Cooper JS, Forastiere A and Ang KK: Factors associated with severe late toxicity after concurrent chemoradiation for locally advanced head and neck cancer: An RTOG analysis. J Clin Oncol 26: 3582-3589, 2008

8. Bjordal K, Hammerlid E, Ahlner-Elmqvist M, de Graeff A, Boysen M, Evensen JF, Biörklund A, de Leeuw JR, Fayers PM, Jannert M, et al: Quality of life in head and neck cancer patients: Validation of the european organization for research and treatment of cancer quality of life questionnaire-H\&N35. J Clin Oncol 17: 1008-1019, 1999.

9. Westra WH, Taube JM, Poeta ML, Begum S, Sidransky D and Koch WM: Inverse relationship between human papillomavirus-16 infection and disruptive p53 gene mutations in squamous cell carcinoma of the head and neck. Clin Cancer Res 14: 366-369, 2008.

10. Chera BS, Amdur RJ, Tepper J, Qaqish B, Green R, Aumer SL, Hayes N, Weiss J, Grilley-Olson J, Zanation A, et al: Phase 2 trial of De-intensified chemoradiation therapy for favorable-risk human papillomavirus-associated oropharyngeal squamous cell carcinoma. Int J Radiat Oncol Biol Phys 93: 976-985, 2015.

11. Watt SM, Buhring HJ, Rappold I, Chan JY, Lee-Prudhoe J, Jones T, Zannettino AC, Simmons PJ, Doyonnas R, Sheer D and Butler LH: CD164, a novel sialomucin on CD34(+) and erythroid subsets, is located on human chromosome 6q21. Blood 92: 849-866, 1998

12. Doyonnas R, Yi-Hsin Chan J, Butler LH, Rappold I, Lee-Prudhoe JE, Zannettino AC, Simmons PJ, Bühring HJ, Levesque JP and Watt SM: CD164 monoclonal antibodies that block hemopoietic progenitor cell adhesion and proliferation interact with the first mucin domain of the CD164 receptor. J Immunol 165: 840-851, 2000.

13. Kurosawa N, Kanemitsu Y, Matsui T, Shimada K, Ishihama H and Muramatsu T: Genomic analysis of a murine cell-surface sialomucin, MGC-24/CD164. Eur J Biochem 265: 466-472, 1999.
14. Watt SM, Butler LH, Tavian M, Bühring HJ, Rappold I, Simmons PJ, Zannettino AC, Buck D, Fuchs A, Doyonnas R, et al: Functionally defined CD164 epitopes are expressed on CD34(+) cells throughout ontogeny but display distinct distribution patterns in adult hematopoietic and nonhematopoietic tissues. Blood 95: 3113-3124, 2000.

15. Zannettino AC, Bühring HJ, Niutta S, Watt SM, Benton MA and Simmons PJ: The sialomucin CD164 (MGC-24v) is an adhesive glycoprotein expressed by human hematopoietic progenitors and bone marrow stromal cells that serves as a potent negative regulator of hematopoiesis. Blood 92: 2613-2628, 1998.

16. Shi JA, Lu DL, Huang X and Tan W: miR-219 inhibits the proliferation, migration and invasion of medulloblastoma cells by targeting CD164. Int J Mol Med 34: 237-243, 2014.

17. Tang J, Zhang L, She X, Zhou G, Yu F, Xiang J and Li G: Inhibiting CD164 expression in colon cancer cell line HCT116 leads to reduced cancer cell proliferation, mobility and metastasis in vitro and in vivo. Cancer Invest 30: 380-389, 2012.

18. Havens AM, Jung Y, Sun YX, Wang J, Shah RB, Bühring HJ, Pienta KJ and Taichman RS: The role of sialomucin CD164 (MGC-24v or endolyn) in prostate cancer metastasis. BMC Cancer 6: 195, 2006.

19. Guenova E, Ignatova D, Chang YT, Contassot E, Mehra T, Saulite I, Navarini AA, Mitev V, Dummer R and Kazakov DV: Expression of CD164 on malignant T cells in Sézary syndrome. Acta Derm Venereol 96: 464-467, 2016

20. Wysocka M, Kossenkov AV, Benoit BM, Troxel AB, Singer E, Schaffer A, Kim B, Dentchev T, Nagata S, Ise T, et al: CD164 and FCRL3 are highly expressed on CD4+CD26- T cells in Sézary syndrome patients. J Invest Dermatol 134: 229-236, 2014.

21. Huang AF, Chen MW, Huang SM, Kao CL, Lai HC and Chan JY: CD164 regulates the tumorigenesis of ovarian surface epithelial cells through the SDF-1 $\alpha /$ CXCR4 axis. Mol Cancer 12: 115, 2013.

22. Matsui T, Kurosawa N, Hibi K, Akiyama S, Kasai Y, Sakamoto J, Ito K, Nakao A and Muramatsu T: The ratio of splicing variants of MGC-24/CD164, a sialomucin, correlates with the metastatic potential of colorectal carcinomas. J Biochem 127: 1103-1107, 2000.

23. Edge SB and Compton CC: The american joint committee on cancer: The 7th edition of the AJCC cancer staging manual and the future of TNM. Ann Surg Oncol 17: 1471-1474, 2010.

24. Marcial VA, Pajak TF, Mohiuddin M, Cooper JS, al Sarraf M, Mowry PA, Curran W, Crissman J, Rodríguez $M$ and Vélez-García E: Concomitant cisplatin chemotherapy and radiotherapy in advanced mucosal squamous cell carcinoma of the head and neck. Long-term results of the radiation therapy oncology group study 81-17. Cancer 66: 1861-1868, 1990.

25. van den Bent MJ, van Putten WL, Hilkens PH, de Wit R and van der Burg ME: Retreatment with dose-dense weekly cisplatin after previous cisplatin chemotherapy is not complicated by significant neuro-toxicity. Eur J Cancer 38: 387-391, 2002.

26. Mazieres J, Brugger W, Cappuzzo F, Middel P, Frosch A, Bara I, Klingelschmitt $\mathrm{G}$ and Klughammer B: Evaluation of EGFR protein expression by immunohistochemistry using $\mathrm{H}$-score and the magnification rule: Re-analysis of the SATURN study. Lung Cancer 82: 231-237, 2013

27. McGuckin CP, Forraz N, Baradez MO, Lojo-Rial C, Wertheim D, Whiting K, Watt SM and Pettengell R: Colocalization analysis of sialomucins CD34 and CD164. Stem Cells 21: 162-170, 2003.

28. Jorgensen-Tye B, Levesque JP, Royle L, Doyonnas R, Chan JY, Dwek RA, Rudd PM, Harvey DJ, Simmons PJ and Watt SM: Epitope recognition of antibodies that define the sialomucin, endolyn (CD164), a negative regulator of haematopoiesis. Tissue Antigens 65: 220-239, 2005.

29. Chen AY and Myers JN: Cancer of the oral cavity. Dis Mon 47: 275-361, 2001. 